\title{
Apigenin inhibits migration and invasion via modulation of epithelial mesenchymal transition in prostate cancer
}

\author{
YI ZHU, JIAN WU, SHIQI LI, XIAO WANG, ZHEN LIANG, XIANGLAI XU, XIN XU, \\ ZHENGHUI HU, YIWEI LIN, HONG CHEN, JIE QIN, QIQI MAO and LIPING XIE \\ Department of Urology, The First Affiliated Hospital, School of Medicine, \\ Zhejiang University, Hangzhou, Zhejiang 310003, P.R. China
}

Received December 20, 2013; Accepted October 1, 2014

DOI: $10.3892 / \mathrm{mmr} .2014 .2801$

\begin{abstract}
The mortality rate associated with prostate cancer is mainly due to metastases rather than primary organ-confined disease. Decreasing the incidence of metastasis is important in treating prostate cancer. 4',5,7-trihydroxyflavone (apigenin) has been demonstrated to be effective in inhibiting several types of cancer. The aim of this study was to investigate the effect and mechanism of apigenin on the movement of prostate cancer cells. In the present study, DU145 cells were treated with varying concentrations of apigenin for different time periods. Cell viability was evaluated using an MTT assay. Cell motility and invasiveness were assayed using wound healing assays and a Matrigel migration and invasion assay. Flow cytometric and western blot analyses were performed to examine the cell cycle and signaling pathways. The results demonstrated that apigenin suppressed the proliferation and inhibited the migration and invasive potential of the DU145 prostate cancer cells in a dose- and time-dependent manner, which was associated with epithelial mesenchymal transition. These findings suggested that apigenin may be effective in treating human prostate cancer.
\end{abstract}

\section{Introduction}

In American males, prostate cancer is the most common noncutaneous malignancy and is the second leading cause of cancer-associated mortality (1). In 2013, the American Cancer Society predicted the diagnosis of $\sim 238,590$ novel cases of prostate cancer in the USA with 29,720 fatalities $(2,3)$. The majority of prostate cancer-associated mortality is attributed to metastatic disease rather than primary, organ-confined pros-

Correspondence to: Professor Liping Xie, Department of Urology, The First Affiliated Hospital, School of Medicine, Zhejiang University, 79 Qing Chun Road, Hangzhou, Zhejiang 310003, P.R. China

E-mail: xielp@zju.edu.cn

Key words: apigenin, prostate cancer, motility, invasion, epithelial mesenchymal transition tate cancer $(4,5)$. Previous studies have demonstrated that, due to dietary factors, the incidence of metastatic prostate cancer is lower in Asian males compared with Western males (6) According to these results, it may be possible to identify agents from the differences of Asian and Western food, for use as chemopreventive agents.

The flavonoid, 4',5,7-trihydroxyflavone (apigenin), is one of the most common flavonoids and is widely distributed in several types of fruit and vegetable, including parsley, onions, orange, tea, chamomile, wheat sprouts and seasonings (7). It has been increasingly recognized as a chemopreventive agent against cancer, exhibiting antimutagenic, anti-inflammatory, antiviral and purgative effects (8). The chemopreventive activity of apigenin in multiple organ sites is likely to be associated with its ability to modulate pathways involved in cell cycle control (9), apoptosis $(9,10)$ and signal transduction (11). One important reason why apigenin has become noteworthy as a beneficial and chemopreventive agent is its low intrinsic toxicity (12).

Epithelial mesenchymal transition (EMT) is important in the invasion and metastasis of human cancer (13) EMT is an important process, in which epithelial cells lose their polarity and convert into more motile and invasive mesenchymal phenotypes. Previous studies have demonstrated the inhibitory effect of apigenin on other human cancer cells (14-17). The present study aimed to demonstrate the effect of apigenin on EMT in prostate cancer.

The present study aimed to determine whether apigenin decreased the migration and invasion ability of prostate cancer cells and its underlying mechanism.

\section{Materials and methods}

Reagents and cell culture. Apigenin ( $\geq 99 \%$ pure) and MTT were purchased from Sigma (St. Louis, MO, USA). Primary antibodies against E-cadherin, Snail, vimentin and GAPDH and secondary antibodies were purchased from Santa Cruz Biotechnology, Inc. (Santa Cruz, CA, USA). The antibodies were all rabbit-type and monoclonal. The bicinchoninic acid protein assay kit was obtained from Pierce Biotechnology (Rockford, IL, USA).

The DU145 human prostate cancer cell line was obtained from the Shanghai Institute of Cell Biology, Chinese Academy 
of Sciences (Shanghai, China). The cells were cultured in RPMI-1640 medium (HyClone, Logan, UT, USA) supplemented with $10 \%$ heat-inactivated fetal bovine serum (FBS; JRH Biosciences, Lenexa, KS, USA), $100 \mathrm{U} / \mathrm{ml}$ penicillin and $100 \mathrm{mg} / \mathrm{l}$ streptomycin (Sigma, St. Louis, MO, USA). The cultures were then maintained in a humidified atmosphere of $5 \% \mathrm{CO}_{2}$ at $37^{\circ} \mathrm{C}$.

Cell viability assay. The effect of apigenin on the viability of DU145 cells was evaluated using an MTT assay. The DU145 cells $\left(\sim 10 \times 10^{4}\right)$ were seeded onto 96 -well plates. Following incubation overnight, the cells were treated with apigenin at different concentrations $(0-80 \mu \mathrm{M})$ in dimethyl sulfoxide (DMSO) for 24 and $48 \mathrm{~h}$ in a humidified atmosphere of $5 \%$ $\mathrm{CO}_{2}$ at $37^{\circ} \mathrm{C}$. Following incubation for the indicated duration, MTT ( $20 \mu \mathrm{l}$ of $5 \mathrm{mg} / \mathrm{ml}$ ) was added to each well and incubated at $37^{\circ} \mathrm{C}$ for $4 \mathrm{~h}$. The MTT solution in the medium was then removed. To achieve solubilization of the formazan crystal formed in the viable cells, $150 \mu$ l DMSO was added to each well prior to measuring the absorbance at $490 \mathrm{~nm}$ using an MRX II absorbance reader (Dynex Technologies, Chantilly, VA, USA). The results were expressed as a percentage of growth.

Wound healing assays. Cells were grown to $100 \%$ confluence in 6-well plates following treatment with apigenin. The cell monolayers were wounded through scraping with a micropipette tip and the wound closure was observed after $24 \mathrm{~h}$. Images were captured under a phase-contrast microscope DP80 (Olympus, Tokyo, Japan) immediately or $24 \mathrm{~h}$ after wounding. The experiments were repeated three times.

In vitro invasion and motility assays. The invasion and motility assays were performed, as previously described (18) with minor modifications. The cells were plated onto a 6 -well plate $\left(8 \times 10^{4}\right.$ cells/well). Following incubation overnight, the cells were treated with apigenin at different concentrations $(0-20 \mu \mathrm{M})$ in DMSO for $24 \mathrm{~h}$ and harvested. The treated and control cells were suspended in medium at a concentration of $4 \times 10^{5}$ cells $/ \mathrm{ml}$ and $0.2 \mathrm{ml}$ of the medium with suspended cells was added to the top chamber of uncoated and Matrigel-coated PET (BD Bioscience, Franklin Lakes, NJ, USA) membranes for motility and invasion assays, respectively (24-well insert; $8 \mu \mathrm{m}$ pore size; Millipore, Bedford, MA, USA). The medium (0.6 ml), supplemented with $20 \%$ FBS, was then added to each well of the plate to act as a chemoattractant in the lower chamber. The cells were incubated for $24 \mathrm{~h}$ and any cells that did not migrate through the pores to the lower surface of the membrane were removed using a cotton swab by scraping the upper membrane surface. The cells that migrated to the lower surface of the membrane were fixed in $100 \%$ methanol for $5 \mathrm{~min}$ and stained with $0.1 \%$ crystal violet for 2 min (Sigma). These experiments were performed a minimum of three times.

Cell cycle assay. The cells were plated onto six-well culture dishes at concentrations 80,000 cells/well that were determined to yield $60-70 \%$ confluence within $24 \mathrm{~h}$. The cells were then treated with apigenin at a range of concentrations $(0-80 \mu \mathrm{M})$ in DMSO. After $24 \mathrm{~h}$, the cells were washed twice with phosphate-buffered saline (PBS) and centrifuged at $800 \times \mathrm{g}$ for $5 \mathrm{~min}$. The pellet was fixed with $70 \%$ ethanol for $1 \mathrm{~h}$ at $4{ }^{\circ} \mathrm{C}$. Following washing with PBS, the cells were resuspended with propidium iodide solution $(0.05 \mathrm{mg} / \mathrm{ml})$ containing RNase and incubated in the dark at room temperature for $30 \mathrm{~min}$. The DNA content was then analyzed using an FC500 flow cytometer (BD Bioscience).

Western blot analysis. The cells were harvested $24 \mathrm{~h}$ after treatment with apigenin. These cells were washed and lysed with lysis buffer (10 mmol/1 Tris-hydrochloride, $0.25 \mathrm{~mol} / 1$ sucrose, $5 \mathrm{mmol} / \mathrm{l} \mathrm{EDTA}, 50 \mathrm{mmol} / 1 \mathrm{NaCl}, 30 \mathrm{mmol} / 1$ sodium pyrophosphate, $50 \mathrm{mmol} / 1 \mathrm{NaF}, 1 \mathrm{mmol} / 1 \mathrm{Na}_{3} \mathrm{VO}_{4}, 1 \mathrm{mmol} / 1 \mathrm{PMSF}$ and $2 \%$ cocktail; $\mathrm{pH} 7.5)$. The protein concentration in the resulting lysate was determined using a bicinchoninic acid protein assay (Merck KGaA, Darmstadt, Germany). Appropriate quantities of protein (20-30 $\mu \mathrm{g})$ were separated by electrophoresis on 10-12\% Tris-glycine polyacrylamide gels and transferred onto nitrocellulose membranes. The membranes were inhibited and incubated overnight with the appropriate primary antibody at dilutions according to the manufacturer's instructions. The membranes were subsequently washed and incubated with the corresponding horseradish peroxidase-conjugated secondary antibody at 1:1,000 dilution in Tris-buffered saline-Tween 20 (10 mM Tris-Cl; pH 7.4, $150 \mathrm{mM} \mathrm{NaCl}$ and $0.1 \%$ Tween-20). The bound secondary antibody was then detected using an enhanced chemiluminescence system (Pierce Biotechnology Inc., Rockford, IL, USA).

Statistical analysis. Statistical significance was compared between the various treatment groups and the controls using analysis of variance. $\mathrm{P}<0.05$ was considered to indicate a statistically significant difference. All statistical analyses were performed using Prism software (GraphPad Prism 6; GraphPad, La Jolla, CA, USA).

\section{Results}

Apigenin inhibits cell growth in DU145 cells. The MTT assay revealed that treatment with apigenin with the vehicle $\operatorname{DMSO}(1 \mu \mathrm{l} / \mathrm{ml})$ at varying concentrations $(10-80 \mu \mathrm{M})$ for different time periods (24-48 h), resulted in dose and time-dependent inhibition of DU145 cell growth compared with the untreated control. As is shown in Fig. 1, no significant difference was identified between the untreated control and the vehicle control indicating that DMSO did not affect the proliferation of DU145 cells. Treatment with $10 \mu \mathrm{M}$ apigenin caused minimal change in the viability of the cells, therefore the migration and invasion assays were performed using concentrations of $0-20 \mu \mathrm{M}$ apigenin. With increasing concentration and time, a marked reduction in cell viability was observed, particularly at concentrations of 40 and $80 \mu \mathrm{M}$. The inhibitory concentration $50 \%$ values for apigenin treatment were estimated to be 80.8 and $49.3 \mu \mathrm{M}$ for 24 and $48 \mathrm{~h}$, respectively. These data indicated that apigenin exerted a significant inhibitory effect on the DU145 cells.

Apigenin inhibits DU145 cell migration and invasion. As the low concentration of apigenin did not induce significant DU145 cell death, the DU145 cells were treated with $0-20 \mu \mathrm{M}$ apigenin to detect whether the migration and invasion potential of the 


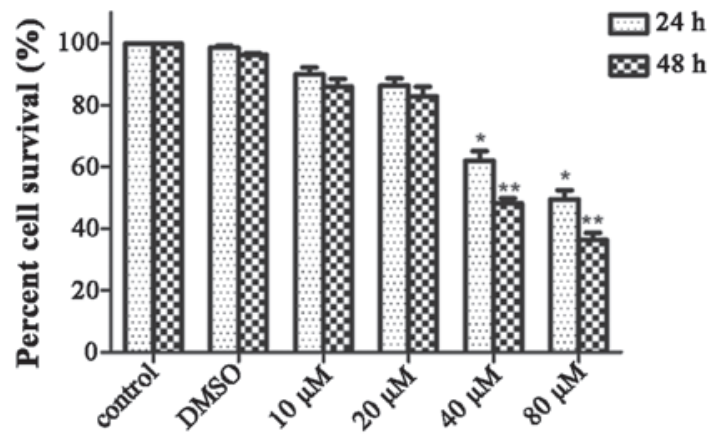

Apigenin concentration

Figure 1. Cytotoxic effects of apigenin in DU145 prostate cancer cells. Cell proliferation and viability were determined using an MTT assay. Reduced cell viability with apigenin treatment (10-80 $\mu \mathrm{M}$ in DMSO) was observed at 24 and $48 \mathrm{~h}$. The data are expressed as the mean \pm standard deviation. ${ }^{*} \mathrm{P}<0.05$ vs. untraeted control; ${ }^{* *} \mathrm{P}<0.01$ vs. untreated control. DMSO, dimethyl sulfoxide.

DU145 cells was decreased at the low concentration. Wound healing assays and transwell assays were performed to observe the function. As shown in Fig. 2, the wound healing assays revealed that apigenin-treated cells exhibited retarded wound closure and fewer stained cells in a dose-dependent manner. As shown in Fig. 3, a significant decrease in motility and invasion was observed compared with the untreated control. These results demonstrated that treatment with apigenin caused significant suppression of the migratory and invasive capability of the DU145 cells.

Apigenin induces G2/M phase cell cycle arrest. The effect of apigenin on cell cycle perturbations was also assessed. Compared with the untreated controls, treatment with apigenin led to a marked arrest of the DU145 cells in the G2/M phase of the cell cycle. Cell cycle analysis demonstrated that the population of control cells in the G2/M phase was $14.46 \%$ and the percentage of cells in the $\mathrm{G} 2 / \mathrm{M}$ phase increased significantly following treatment with apigenin at different concentrations for $24 \mathrm{~h}$ (Fig. 4A). This increase in the population of cells in the $\mathrm{G} 2 / \mathrm{M}$ phase was accompanied by a concomitant decrease in the number of cells in the G1 phase of the cell cycle (Fig. 4B).

Apigenin reverses EMT in DU145 cells. EMT is important in metastasis. The loss of E-cadherin is key in EMT (19), therefore the dose-dependent effects of apigenin on the constitutive protein levels of E-cadherin, Snail and vimentin in DU145 cells was examined. The western blot analysis revealed a significant increase in the expression of E-cadherin, while in sharp contrast, the protein expression of Snail and vimentin was significantly decreased by apigenin treatment in a dose-dependent manner (Fig. 5). These results demonstrated that apigenin reversed the process of EMT.

\section{Discussion}

The present study investigated whether apigenin affected EMT in DU145 prostate cancer cells. Emerging evidence has suggested that EMT is a morphological event that is crucial for tumor progression in terms of its physiological and meta-
$\mathbf{A}$
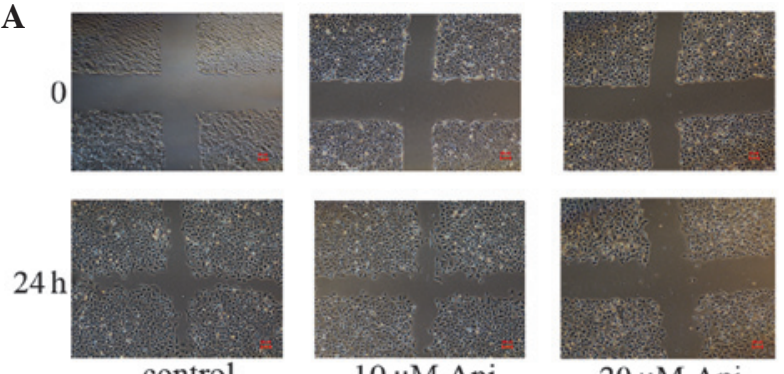

$10 \mu \mathrm{M}$ Api

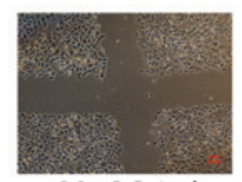

$20 \mu \mathrm{M}$ Api

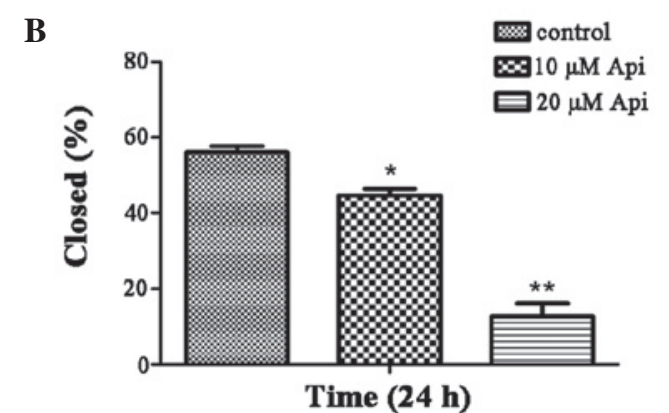

Figure 2. Api suppresses cell motility in a wound healing assay. The DU145 cells were treated with $0-20 \mu \mathrm{M}$ api and wound healing assays were performed with a 24 h recovery period. (A) Representative image. (B) Quantitation of one experiment performed in triplicate. ${ }^{*} \mathrm{P}<0.05$, vs. untreated control, ${ }^{* *} \mathrm{P}<0.01$, vs. untreated control. Api, apigenin.
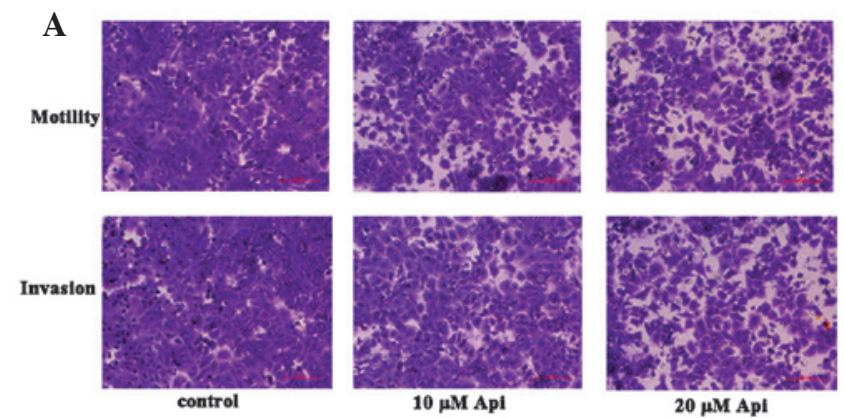

B
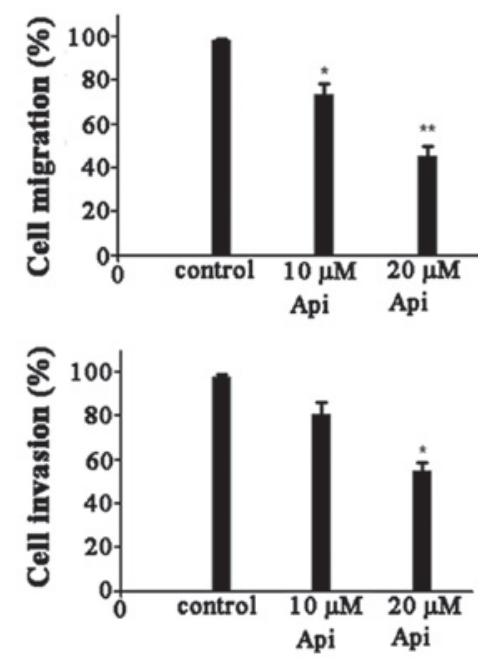

Figure 3. Effect of Api on DU145 cell invasion and migration. The cells treated with $0-20 \mu \mathrm{M}$ Api were induced to move or invade through uncoated or Matrigel-coated transwell membranes. After $24 \mathrm{~h}$, the cells were fixed, stained and counted. (A) Representative image. (B) Quantitation of one experiment performed in triplicate. ${ }^{*} \mathrm{P}<0.05$, vs. untreated control, ${ }^{* *} \mathrm{P}<0.01$, vs. untreated control. Api, apigenin. 
A
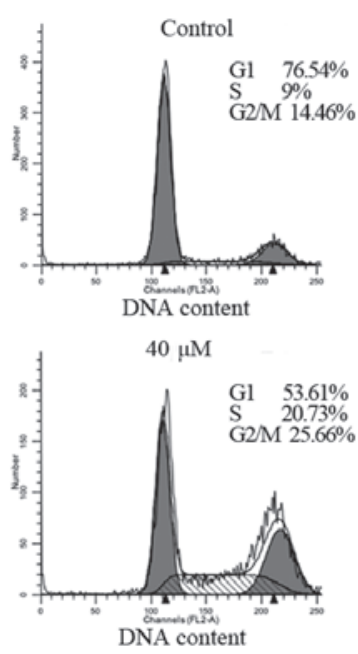

$20 \mu \mathrm{M}$
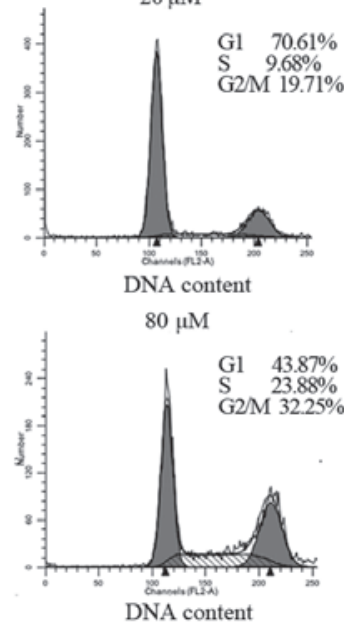

B

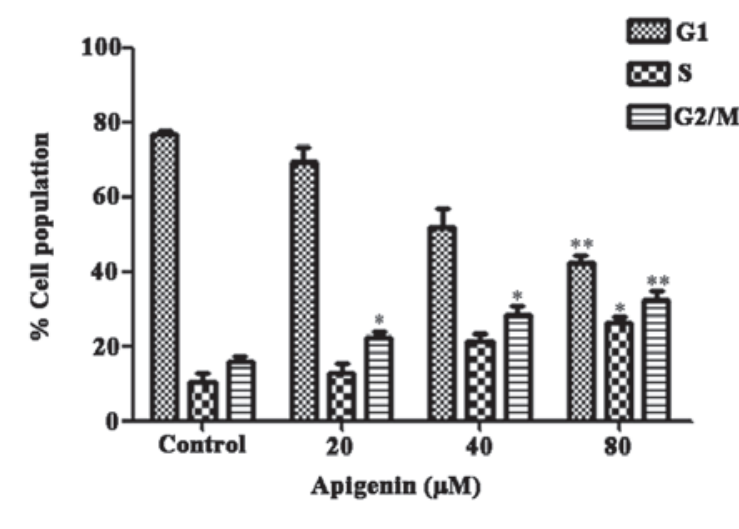

Figure 4. Cell cycle analysis of DU145 prostate cancer cells treated with apigenin. (A) Cells were treated with different concentrations of apigenin for $24 \mathrm{~h}$ and then stained with propidium iodide. The DNA content was analyzed by flow cytometry. G1, S and G2/M indicate cell cycle phase. (B) Marked G2/M phase arrest was observed with a concomitant decrease in the number of cells in the G1 phase of the cell cycle. The percentage of cells in the G2/M phase was quantified from three independent experiments. ${ }^{*} \mathrm{P}<0.05$ and ${ }^{* *} \mathrm{P}<0.01$ vs. the untreated control.

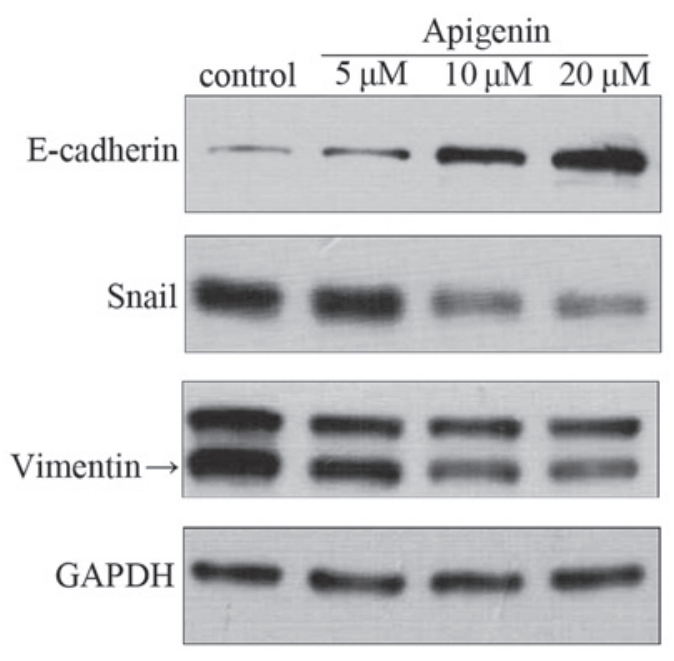

Figure 5. Expression of protein change in cells treated with different concentrations of apigenin for $24 \mathrm{~h}$. Apigenin upregulated the expression of E-cadherin and reduced the expression of Snail and vimentin. A representative blot is shown from three independent experiments with identical results.

static development (20). EMT is defined by the loss of cell-cell adhesion, modification of cell morphology and the increase of cellular migration activity (20). Downregulation of the epithelial marker E-cadherin, the main transmembrane adhesion molecule responsible for cell-to-cell adhesions and tissue organization in epithelial tissue, and upregulation of the mesenchymal marker vimentin is one of the basic mechanisms involved in EMT (21). This suggests that the loss of E-cadherin expression induces the breakdown of adherens junctions and, in addition to other signaling events, promotes changes in the expression of the robust gene (22) and suppresses the dissociation of epithelial cells from their location (23). In the present study, when the DU145 cells were treated with different concentrations of apigenin, the expression of E-cadherin was rescued and that of vimentin was markedly inhibited, indicating that the progression of EMT was reversed and metastatic capability was suppressed.
There is now clear evidence that a number of factors are involved in the induction of EMT and that their signaling pathways communicate extensively with each other and with oncogenes. The activation of Ras, a receptor tyrosine kinase, and its signaling system not only provides a continuous growth stimulus for cancer, but also potentially induces EMT (24). Additionally, all pathways downstream of Ras (phosphoinositide 3-kinase; PI3K, Raf and Ral-GEF) have been demonstrated to induce EMT (25). Transforming growth factor $\beta$, a cytokine produced by mesenchymal stromal and inflammatory cells (26), may be the most extensively investigated of the stromal factors facilitating the induction of malignant cells to undergo EMT. The transcriptional repressors, Snail, Slug, Zeb and Twist also control EMT. Snail and Zeb are zinc-finger transcription factors that bind to the E-boxes of the E-cadherin-encoding gene (CDH1) promoter, thereby repressing the expression of CDH1 (27). In the present study, the downregulation of Snail expression suggested that apigenin inhibited EMT by targeting the Snail regulator. Our previous study demonstrated that apigenin treatment in T24 bladder cancer cells inhibited the PI3K/Akt pathway (28), which suggested that apigenin reversed EMT, possibly through the PI3K/protein kinase B pathway. In future studies, the complex mechanism between apigenin and EMT requires further examination.

Previous studies have also revealed that apigenin is a potent inhibitor of cell-cycle progression in several cell lines $(29,30)$. The present study also measured the effect of apigenin on the cell cycle of DU145 cells and found that apigenin led to $\mathrm{G} 2 / \mathrm{M}$ phase arrest. Although G1 arrest by apigenin in human diploid fibroblasts has been observed previously (30), the present study observed G2/M arrest in apigenin-treated DU145 cells and the difference between these results may be attributed to the types of cell assessed.

In conclusion, the present study demonstrated that apigenin induced cell death and inhibited the migration and invasion ability of DU145 prostate cancer cells in a dose and time-dependent manner. Apigenin led to a reversal of EMT 
and also caused G2/M phase arrest. All these results indicated that apigenin can be used as a chemopreventive agent in prostate cancer. To the best of our knowledge, this is the first study demonstrating the effect of apigenin on EMT in prostate cancer in vitro. However, further investigation of the mechanism underlying apigenin-treated cell inhibition is required.

\section{Acknowledgements}

This study was supported by the National Key Clinical Specialty Construction Project of China, Key Medical Disciplines of Zhejiang Province, Combination of Traditional Chinese and Western Medicine Key Disciplines of Zhejiang Province (no. 2012-XK-A23), the National Natural Science Foundation of China (no. 81101717), the Natural Science Foundation of Zhejiang Province (nos. LY13H160009 and Y2110120) and the Medical Scientific Research Foundation of Zhejiang Province, China (no. 2013KYB100).

\section{References}

1. Siegel R, Naishadham D and Jemal A: Cancer statistics, 2013 CA Cancer J Clin 63: 11-30, 2013.

2. Siegel R, DeSantis C, Virgo K, et al: Cancer treatment and survivorship statistics, 2012. CA Cancer J Clin 62: 220-241, 2012.

3. American Cancer Society: Prostate cancer facts and statistics. http://www.cancer.org/cancer/prostatecancer/index. (Accessed on November 13, 2013).

4. Cook LS, Goldoft M, Schwartz SM and Weiss NS: Incidence of adenocarcinoma of the prostate in Asian immigrants to the United States and their descendants. J Urol 161: 152-155, 1999.

5. Arya M, Bott SR, Shergill IS, Ahmed HU, Williamson M and Patel HR: The metastatic cascade in prostate cancer. Surg Oncol 15: 117-128, 2006.

6. Adlercreutz H: Western diet and Western diseases: some hormonal and biochemical mechanisms and associations. Scand J Clini Lab Invest Suppl 50: 3-23, 1990.

7. Birt DF, Mitchell D, Gold B, Pour P and Pinch HC: Inhibition of ultraviolet light induced skin carcinogenesis in SKH-1 mice by apigenin, a plant flavonoid. Anticancer Res 17: 85-91, 1997.

8. Yang CS, Landau JM, Huang MT and Newmark HL: Inhibition of carcinogenesis by dietary polyphenolic compounds. Annu Rev Nutr 21: 381-406, 2001

9. Patel D, Shukla S and Gupta S: Apigenin and cancer chemoprevention: Progress, potential and promise (review). Int J Oncology 30: 233-245, 2007.

10. Shukla S and Gupta S: Molecular targets for apigenin-induced cell cycle arrest and apoptosis in prostate cancer cell xenograft. Mol Cancer Ther 5: 843-852, 2006.

11. Van Dross RT, Hong X and Pelling JC: Inhibition of TPA-induced cyclooxygenase-2 (COX-2) expression by apigenin through downregulation of Akt signal transduction in human keratinocytes. Mol Carcinog 44: 83-91, 2005.
12. Gupta S, Afaq F and Mukhtar H: Selective growth-inhibitory, cell-cycle deregulatory and apoptotic response of apigenin in normal versus human prostate carcinoma cells. Biochem Biophys Res Commun 287: 914-920, 2001.

13. Yilmaz M and Christofori G: EMT, the cytoskeleton, and cancer cell invasion. Cancer Metastasis Rev 28: 15-33, 2009.

14. Caltagirone S, Rossi C, Poggi A, et al: Flavonoids apigenin and quercetin inhibit melanoma growth and metastatic potential. Int J Cancer 87: 595-600, 2000.

15. Wang IK, Lin-Shiau SY and Lin JK: Induction of apoptosis by apigenin and related flavonoids through cytochrome $\mathrm{c}$ release and activation of caspase-9 and caspase-3 in leukaemia HL-60 cells. Eur J Cancer 35: 1517-1525, 1999.

16. Wang W, Heideman L, Chung CS, Pelling JC, Koehler KJ and Birt DF: Cell-cycle arrest at G2/M and growth inhibition by apigenin in human colon carcinoma cell lines. Mol Carcinog 28: 102-110, 2000.

17. Yin F, Giuliano AE, Law RE and Van Herle AJ: Apigenin inhibits growth and induces $\mathrm{G} 2 / \mathrm{M}$ arrest by modulating cyclin-CDK regulators and ERK MAP kinase activation in breast carcinoma cells. Anticancer Res 21: 413-420, 2001.

18. Albini A, Iwamoto Y, Kleinman HK, et al: A rapid in vitro assay for quantitating the invasive potential of tumor cells. Cancer Res 47: 3239-3245, 1987.

19. Jaggi M, Johansson SL, Baker JJ, Smith LM, Galich A and Balaji KC: Aberrant expression of E-cadherin and beta-catenin in human prostate cancer. Urol Oncol 23: 402-406, 2005.

20. Thiery JP: Epithelial-mesenchymal transitions in tumour progression. Nat Rev Cancer 2: 442-454, 2002.

21. Huber MA, Kraut N and Beug H: Molecular requirements for epithelial-mesenchymal transition during tumor progression. Curr Opin Cell Biol 17: 548-558, 2005.

22. Sarkar FH, Li Y, Wang Z and Kong D: Pancreatic cancer stem cells and EMT in drug resistance and metastasis. Minerva Chir 64: 489-500, 2009.

23. Vleminckx K, Vakaet L Jr, Mareel M, Fiers W and van Roy F: Genetic manipulation of E-cadherin expression by epithelial tumor cells reveals an invasion suppressor role. Cell 66: 107-119, 1991.

24. Bates RC and Mercurio AM: The epithelial-mesenchymal transition (EMT) and colorectal cancer progression. Cancer Biol Ther 4: 365-370, 2005.

25. Thiery JP: Epithelial-mesenchymal transitions in development and pathologies. Curr Opin Cell Biol 15: 740-746, 2003.

26. Branton MH and Kopp JB: TGF-beta and fibrosis. Microbes Infect 1: 1349-1365, 1999.

27. Chaffer CL, Brennan JP, Slavin JL, Blick T, Thompson EW and Williams ED: Mesenchymal-to-epithelial transition facilitates bladder cancer metastasis: role of fibroblast growth factor receptor-2. Cancer Res 66: 11271-11278, 2006.

28. Zhu Y, Mao Y, Chen $\mathrm{H}$, et al: Apigenin promotes apoptosis, inhibits invasion and induces cell cycle arrest of T24 human bladder cancer cells. Cancer Cell Int 13: 54, 2013.

29. Lepley DM, Li B, Birt DF and Pelling JC: The chemopreventive flavonoid apigenin induces $\mathrm{G} 2 / \mathrm{M}$ arrest in keratinocytes. Carcinogenesis 17: 2367-2375, 1996.

30. Lepley DM and Pelling JC: Induction of p21/WAF1 and G1 cell-cycle arrest by the chemopreventive agent apigenin. Mol Carcinog 19: 74-82, 1997. 